\title{
An Innovative Prosopis Cineraria Pod Aqueous Waste as Natural Inhibitor for Enhancing Unsaturated Lipids Production in Yeast Cell Using Banana Peel
}

Shivani Chaturvedi ( $\sim$ shivani.d123@gmail.com)

Indian Institute of Technology Delhi https://orcid.org/0000-0002-7318-8599

\section{Prashant Kumar}

CIMAP: Central Institute of Medicinal and Aromatic Plants CSIR

\section{Deepak Kumar}

CIMAP: Central Institute of Medicinal and Aromatic Plants CSIR

\section{Naziya Syed}

CIMAP: Central Institute of Medicinal and Aromatic Plants CSIR

\section{Madhuri Gupta}

CIMAP: Central Institute of Medicinal and Aromatic Plants CSIR

\section{Chandan Singh Chanotiya}

CIMAP: Central Institute of Medicinal and Aromatic Plants CSIR

\section{Prasant Kumar Rout}

CIMAP: Central Institute of Medicinal and Aromatic Plants CSIR

\section{Sunil Kumar Khare}

IITD: Indian Institute of Technology Delhi

\section{Research Article}

Keywords: Banana peel, Prosopis cineraria, Natural inhibitor, Oleaginous yeast, Unsaturated lipid, Polyphenols

Posted Date: September 7th, 2021

DOl: https://doi.org/10.21203/rs.3.rs-819489/v1

License: (1) This work is licensed under a Creative Commons Attribution 4.0 International License. Read Full License 
Version of Record: A version of this preprint was published at Waste and Biomass Valorization on March 2nd, 2022. See the published version at https://doi.org/10.1007/s12649-022-01741-w. 


\section{Abstract}

Single cell oil (SCO) produced by yeast is an attractive alternative due to higher lipid yield in a limited space with naturally manipulating the quality. In the present study, the banana peel is used as a source of carbon for biotransformation by Rhodotorula mucilaginosa to lipid. Further, the quality and quantity of the lipid are enhanced using discarded aqueous Prosopis cinerareia pod extract as a natural inhibitor. $P$. cineraria aqueous extract was quantified using HPLC, and it was contained phenyl propenoids such as epicatechin $(0.068 \%)$, gallic acid $(0.29 \%)$, quercetin $(0.34 \%)$, epigallocatechin $(0.091 \%)$, rutin $(0.141 \%)$, ellagic acid $(0.141 \%)$, along with glucose $(1.22 \%)$, and sucrose $(2.36 \%)$. The sucrose and glucose were isolated from the aqueous extract, and further characterized through NMR and TGA. Hence, this natural inhibitor is found advantageous as compared to the chemical inhibitor (statin) in terms of lipid production with desirable quality. It is achieved by inhibitors blocking the yeast competitive mevalonate pathway to promote higher lipid accumulation in the microbial cells. The anti-chlostrolemic activity of this natural inhibitor might be influenced lipid accumulation by blocking the mevalonate pathway. Thus, the reducing sugars as well as phenylpropenoids were worked in synergy to enhance accumulation of unsaturated lipid in the microbial cells. Phenylpropenoids may inhibit the key enzyme HMG reductase, which controls the mevalonate pathway for ergosterol formation to induce lipid accumulation. This lipid isolation from yeast cell was improved using green solvent viz. liquid- $\mathrm{CO}_{2}$. This lquid- $\mathrm{CO}_{2}$ extract was enriched with unsaturated lipid (46.96\%) including w-fatty acids such as linoleic (17.61\%) and linolenic $(5.35 \%)$. Thus, the SCO is produced using food waste as the source of carbon as well as an inhibitor, and this lipid is treated as natural to find suitable for nutritional purposes.

\section{Introduction}

The per capita consumption of vegetable oil is in an increasing trend due to modern food practices. Conventional oil-seed production has attained a plateau; hence the alternative non-conventional source of lipids is the need of the hour [1]. Fruits peels are a rich source of starch and protein to display an important role in the lipid production by oleaginous yeast [2]. The cultivation of bananas in India occupies around 830.5 thousand ha area with total production is approximately $31.78 \times 10^{6}$ tons in the year 2020 [3]. Since India is a leading cultivar of the banana crop; hence its peel waste is produced in bulk. This waste could be utilized as a substrate for lipid production, which is again used as a food supplement.

Oleaginous yeast like Rhodotorula mucilaginosa $(\mathrm{Y}-1)$ was found to promising for lipid production in our earlier studies [2, 4, 5]. Further enhancing the lipid yield, our study is focused on its metabolic pathway for lipid synthesis, and in this regard, the mevalonate pathway is very important. If the competitive mevalonate pathway was blocked with the help of inhibitors, then the flux shifted towards triacylglyceride (TAG) biosynthesis. The pigments like ergosterol, $\beta$-carotenoids were produced by the mevalonate pathway, and the key enzyme for this is 3-hydroxy-3-methyl-glutaryl (HMG) reductase enzyme. In our previous study, it was reported that the inhibition of this enzyme by chemical inhibitor rosuvastatin was helpful in the down-regulation of HMG reductase enzyme, this resulted to enhance the lipid production in 
the yeast cell [4]. The cholesterol production in human and ergosterol synthesis in yeast follows the same pathway, so targeting HMG reductase enzyme inhibition lowers the production of cholesterol and ergosterol. The prolonged use of statin in humans has been shown some side effects [6]. On the other hand, plant origin natural inhibitor has no side effect, and it can substitute the chemical inhibitor. In this regard, desert grown vegetation Prosopis cineraria have been known to possess potent bioactive compounds $[7,8,9]$. Various parts of this plant were found to have alkaloids, saponins, flavonoids, polyphenols, and tannins. Thus, it is selected as a natural inhibitor for increasing microbial oil production. This study was focused to inhibit the HMG-CoA reductase by adding natural inhibitor $P$. cineraria pod extract in the media with banana peel as a carbon source for the production of lipid. The result of the natural inducer was compared with the chemical inhibitor (rosuvastatin) in terms of biomass, oil yield and quality of the oil. Besides this, the microbial oil was extracted by conventional extraction processes and compared with the green extraction process viz. liquid $\mathrm{CO}_{2}$.

\section{Materials And Methods}

\subsection{Chemicals and real-life substrates}

All the chemicals such as dextrose, peptone, malt extract, yeast extract, sodium citrate, etc were purchased from Merck Darmstadt (Germany). Inhibitor rosuvastatin tablets (Cipla, India) of $5 \mathrm{mg}$ potency was procured from Apollo pharmacy, New Delhi. Other HPLC grade solvents were supplied by SRL Ltd. (India).

\subsection{Preparation of substrate}

Banana peel (at its green stage) was collected from the local market, it was then sun-dried and pulverized with the help of a domestic mixer grinder. This dried powder was used in the experiment as the carbon source for the growth of the yeast. The dried $P$. cineraria pod was procured from the Bikaner district situated in the desert of Rajasthan, India, and pulverized it for the extraction purpose. Pods $(100 \mathrm{~g})$ were soaked in $250 \mathrm{~mL}$ autoclaved HPLC water overnight and then filtered. The aqueous filtrate was added to the media, and then it was autoclaved for $6 \mathrm{~h}$.

\subsection{Conditions for the culture development}

The laboratory culture of $R$. mucilaginosa $(\mathrm{Y}-1)$ was acquired and maintained on malt extract, dextrose, yeast extract, peptone (MGYP) and agar slants with a ratio of $0.3: 2.5: 0.3: 0.5$, respectively at $4^{\circ} \mathrm{C}$, and it was sub-cultured in the regular interval of 1 month. All the media were autoclaved at $15 \mathrm{lbs}$ pressure for 15 min before inoculation. The rosuvastatin has been selected because of its distinct orange/ redcoloured pigments to use for visual monitoring by colour development. Then, it was transferred a loopful of sterilized MGYP broth $(\mathrm{pH} 7)$ and incubated for 2 days in an incubator cum shaker (Model lab Therm, Kuhner, Switzerland) at $28^{\circ} \mathrm{C}$ with vibrating at $120 \mathrm{rpm}$. Media was prepared using $8 \%$ banana peel, $0.05 \%$ $\mathrm{MgSO}_{4}, 0.1 \% \mathrm{~K}_{2} \mathrm{HPO}_{4}(\mathrm{w} / \mathrm{v})$, and this was used for the submerged fermentation. 


\subsection{Elemental and functional group evaluation of the substrate}

\subsubsection{ICP-OES analysis of banana peel}

The dried banana peel substrate was analyzed for their compositional analysis. The ICP-OES was used for the elemental analysis of an acid digestible sample using PerkinElmer, Optima 530V, USA machine. The standard mixture of $\mathrm{Ca}, \mathrm{Mg}, \mathrm{Al}, \mathrm{Mn}, \mathrm{K}, \mathrm{B}, \mathrm{Sr}$, Cu and $\mathrm{P}$ were used for the quantitative estimation.

\subsubsection{FT-IR spectra of banana peel}

The PerkinElmer FT-IR spectrum Gx was used for the qualitative estimation of a different class of compounds. For that, $10 \mathrm{mg}$ of banana peel was thoroughly mixed with $150 \mathrm{mg}$ dried $\mathrm{KBr}$ for the preparation of pellets. Spectra were recorded in between $600-4000 \mathrm{~cm}^{-1}$ in the range of $2 \mathrm{~cm}^{-1}$.

\subsubsection{Quantification of carbohydrates and phenylpropanoids}

$P$. cineraria pod aqueous extract was freeze-dried, and the extract was used for reducing sugar analysis. The dried $P$. cineraria pod aqueous extract was hydrolyzed as per the standard NREL protocol [10]. The sample was neutralized using $\mathrm{NaHCO}_{3}$ and kept in refrigerator for quantification. The reducing sugars were quantified using RP-HPLC-RI system of Waters (Milford MA, USA) make. The system was equipped with $5 \mathrm{ml}$ capacity binary pumps (Waters model 515), a rheodyne (model 7125) manual injector, and Refractive Index (RI) detector. The chromatograms were obtained on Empower Pro software (Waters, USA). HPX-87H Bio-Rad Aminex column (300 mm $\times 3.9 \mathrm{~mm}$ ) of water (USA) make at $80^{\circ} \mathrm{C}$ was used for the analysis of carbohydrates. An isocratic solvent system comprising of degassed acetonitrile: water (70:30) of 20 min run time was used for quantification. The flow rate was $0.5 \mathrm{ml} / \mathrm{min}$ throughout the run with a column temperature $\left(60^{\circ} \mathrm{C}\right)$ and sample injected volume of $20 \mu \mathrm{L}$. All samples were accurately weighed and dissolved in water with thorough sonication, and filtration before injecting into the system. For the analysis of sugars, $2 \mathrm{mg}$ of each glucose and sucrose were separately diluted in $1 \mathrm{ml}$ of water.

In addition, the dried $P$. cineraria pod aqueous extract was used for quantification of phenyl propenoids using RP-HPLC-PDA system of the above Watersmake. The system was equipped with PDA detector,

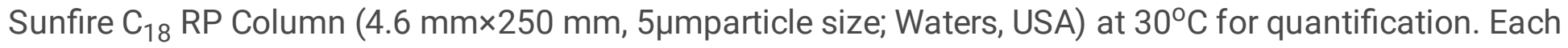
standard (1 mg) such as epicatechin, gallic acid, quercetin, epigallocatechin, rutin and ellagic acid was dissolved in $1 \mathrm{ml}$ of methanol to make the standard solutions at a concentration of $1 \mathrm{mg} / \mathrm{mL}$. Sample analysis was carried out at $30^{\circ} \mathrm{C}$ using a gradient solvent system. The mobile phase for gradient elution comprised of solvent A (Methanol, $100 \%)$ and B (0.1\% TFA in water), following profile was found best suitable for peak resolution and separation of the individual compound in the sample as $0-25 \mathrm{~min}(25 \%$ A to $35 \% \mathrm{~A}), 25-50 \mathrm{~min}(35 \% \mathrm{~A}$ to $50 \% \mathrm{~A}), 50-60 \mathrm{~min}(50 \% \mathrm{~A}$ to $80 \% \mathrm{~A})$, and $60-70 \mathrm{~min}(80 \% \mathrm{~A}$ to $100 \%$ A) at a flow rate of $0.8 \mathrm{~mL} / \mathrm{min}$, and $210-280 \mathrm{~nm}$ wavelengths were used for the quantification.

\subsubsection{Confirmation of compounds through HRMS analysis}


High resolution mass was recorded using 6545 QTOF LC/MS of Agilent technologies system. The peaks were identified through high-resolution mass spectra along with their isotopic mass analysis.

\subsection{Quantitative evaluation of yeast biomass}

Yeast biomass was collected with the help of Millipore $(0.45 \mu \mathrm{m})$ membrane filtration system after completion of the incubation period. The accumulated biomass over the membrane was dried at $80^{\circ} \mathrm{C}$, and the weight was taken by gravimetrically for calculation of the yeast cell weight.

\subsubsection{Cell-morphology visualization of $R$. mucilaginosa}

The morphological difference of $R$. mucilaginosa was closely observed with the help of SEM images (Model EVO 50, ZEISS EVO series, Germany) as per the reported protocol [11]. The samples were accumulated at the log phase of the yeast cell growth. On the gold-plated metallic stub, the cell biomass sample was kept with the help of two-sided adhesive carbon tape for imaging.

\subsection{Extraction of lipid through different extraction techniques}

The grinded and dried biomass was used for the isolation of lipid through different processes.

\subsubsection{Soxhlet Extraction}

In the soxhlet extraction or hot extraction process, $8 \mathrm{~g}$ of dried biomass was taken in a cellulose thimble, which was extracted in hexane or ethylacetate for $7 \mathrm{~h}$. Then, filtered the solution and evaporated the solvent in a rotary evaporator at $35^{\circ} \mathrm{C}$ under 150 mbar vacuum.

\subsubsection{Cold percolation method for lipid extraction}

In the cold percolation method, the sample $(8 \mathrm{~g})$ was treated with ethyl hexane $(50 \mathrm{~mL})$ and kept for $4 \mathrm{~h}$. The hexane solution was filtered out and the marc was extracted (50 $\mathrm{mL} \times 2$ ) times successively in similar conditions. The hexane solutions were pulled together and evaporated the solvent in a rotary evaporator under a vacuum. The weights of the collected samples were recorded.

\subsubsection{Extraction of lipids through liquid $\mathrm{CO}_{2}$ extraction}

The liquid $\mathrm{CO}_{2}$ extraction was carried out in a high-pressure stainless-steel vessel. The experimental setup and methodology have appeared in our earlier publication [12]. In brief, the modified glass apparatus was placed inside this pressure vessel for keeping the biomass in the upper soxhlet type unit to follow a beaker just below it. The pressure was maintained in the vessel to 70 bar at $15^{\circ} \mathrm{C}$, and it was placed in a water bath maintained at $35^{\circ} \mathrm{C}$. First, the $\mathrm{CO}_{2}$ was condensed and collected in the soxhlet to fill up to the siphon level. Then, the $\mathrm{CO}_{2}$ along with dissolved lipid was siphoned to the lower beaker. Again, the liquid $\mathrm{CO}_{2}$ was evaporated from the lower beaker due to heat transform from the hot water $\left(35^{\circ} \mathrm{C}\right)$ bath. This cycle of evaporation and condensation was continued for $4 \mathrm{~h}$, and each cycle was completed around 6 
min to ensure the complete extraction of lipid. Then, the $\mathrm{CO}_{2}$ was slowly released from the apparatus to collect the lipids from the beaker.

\subsection{Physcio-chemical analysis of lipids}

Acid value, saponification value and iodine number are the physico-chemical properties of the lipid [4]. These values are determined as per the standard titration methods [1]

\subsubsection{Gas chromatography (GC) and GC-mass spectrometry (MS) analysis}

The extracted lipid was converted into fatty acid methyl ester (FAME), and qualitative analysis was carried out by PerkinElmer auto system XL Gas chromatography along with a flame ionization detector (FID). The capillary column of Elite wax of $30 \mathrm{~m} \times 0.25 \mathrm{~mm} \times 0.25 \mu \mathrm{m}$ film thickness was used for the analysis. Hydrogen was used as carrier gas with a column head pressure of $7.5 \mathrm{psi}$. Sample $(0.1 \mu \mathrm{L})$ was injected in the port with a split ratio of 1:40. The injector and FID temperature were maintained at $240^{\circ} \mathrm{C}$ with a column linear temperature program of $40^{\circ} \mathrm{C}$ to $120^{\circ} \mathrm{C}$ (rate of $\left.3^{\circ} \mathrm{C} / \mathrm{min}\right), 120$ to $140^{\circ} \mathrm{C}\left(2^{\circ} \mathrm{C} / \mathrm{min}\right.$ ) and 140 to $230^{\circ} \mathrm{C}\left(5^{\circ} \mathrm{C} / \mathrm{min}\right)$. PerkinElmer SQ8C MS interfaced with a Turbomass Quadrupole mass spectrometer Clarus $680 \mathrm{GC}$ was used for the GC/MS analysis with similar conditions as mentioned above. Helium was used as a carrier gas with a constant pressure of $1.5 \mathrm{psi}$. The injector and transfer line temperature were kept at $240^{\circ} \mathrm{C}$, electron ionization (EI) $70 \mathrm{eV}$, and mass scan range $40-450 \mathrm{amu}$.

\subsubsection{Nuclear magnetic resonance spectroscopy (NMR) analysis}

The NMR analysis was performed with the help of Brucker NMR500 MHz machine. For the analyses of samples, $8 \mathrm{mg}$ of lipid was dissolved in $\mathrm{CDCl}_{3}$ for the recording of proton NMR. In this, the internal standard was TMS, and 200 scans were performed for recording the spectra. The chemical shifts $(\delta)$ of protons were interpreted for getting information about the nature of protons.

\subsubsection{Thermo gravimetric analysis (TGA) of the lipid}

The TGA of lipid was run using the equipment of Mettler-Toledo, TGA/DSC 1 make. For this, $5 \mathrm{mg}$ sample was taken in a silica crucible. Devolatization study was conducted in between 50 to $550^{\circ} \mathrm{C}$ at the rate of $10^{\circ} \mathrm{C}$ per min. Nitrogen was used as a purge gas with a flow rate of $60 \mathrm{~mL} / \mathrm{min}$. In a similar methodology, the standard soybean oil devolatilization behavior was studied for comparison purposes. The spectra were obtained according to the volatility of the samples, and their first derivatives were computed using software for the clear interpretation of devolatilization behavior.

\subsection{Isolation of carbohydrates from $P$. cineraria pod}

Pods powder $\left(300 \mathrm{~g}\right.$ ) was extracted with $1 \mathrm{~L}$ of hexane at $50^{\circ} \mathrm{C}$ for defatting. Then, the solution was decanted to follow a quick wash with $500 \mathrm{~mL}$ of fresh hexane. The combined extract was evaporated at $40^{\circ} \mathrm{C}$ under 160 mbar vaccum using Buchi (Switzerland make) rotatory evaporator. The weight of the 
dried extract was recorded and kept at $4^{\circ} \mathrm{C}$ until further analysis. The defatted pod powder was then again extracted with $1 \mathrm{~L}$ of methanol-water solvent system $(4: 1)$ at $50^{\circ} \mathrm{C}$ for $4 \mathrm{~h}$. Then, the solution was decanted and repeated the same extraction procedure for two more times. The combined extract was evaporated at $65^{\circ} \mathrm{C}$ under $80 \mathrm{mbar}$ vaccum. Dried extract was weighed and kept at $4{ }^{\circ} \mathrm{C}$ until further analysis. The extract was dissolved in a minimum amount of methanol and kept at room temperature to furnish the colorless crystals (Scheme 1). Crystals were centrifuged out at $10000 \mathrm{rpm}$ and thoroughly washed using methanol and subjected to different spectroscopic analysis. The sugars are quantified as described in Sect. 2.3.

\subsection{Statistical significance}

The data are recorded as an average of three repeated experiments. The statistical significance was validated by 16.0 software of SPSS data editor (Microsoft). The correlation was established between the dependent and independent variables using bivariate Pearson, two tailed mode for $p<0.01$ and $p \otimes 0.05$ with $99 \%$ and $95 \%$ ofassurance level, respectively.

\section{Results}

The data were taken in triplicate and the average values were represented. The appropriate days for the collection of samples were decided based on the growth curve of yeast culture.

\subsection{Characterization of Banana peel and $P$. cineraria aqueous extract}

The banana peel was contained glucose and sucrose ( $>30 \%)$, along with protein $(4.41 \%)$. The banana peel contained good amounts of micronutrients (mg/ $100 \mathrm{~g})$ such as K (2795.5), Ca (316.2), Mg (165.7), $\mathrm{P}$ (71), B (11.2), Al (4.8), Mn (2.4), Fe (1.5), and Cu (0.4) (Table 1a). Most of the micronutrients were increased, when the media is treated with $P$. cineraria aqueous extract. On the contrary, there is no significant change of nutrients, when media is treated with chemical inhibitor (Table 1a). On the other hand, $P$. cineraria aqueous extract $(100 \mathrm{mg} / \mathrm{mL})$ is contained glucose $(1.22 \%)$, sucrose $(2.36 \%)$ with proteins $(3.77 \%$ ) (Table $1 \mathrm{~b}$ ), while pod contains $5.44 \%$ of protein. The phyenylpropenoids contained in the aqueous extract are presented in Table 1c, Figure S4-S5. 
Table 1

a: Micronutrients status in the fresh dried banana peel (Fba), spent banana peel biomass with $P$. cineraria waste water $(\mathrm{NInSc})$, spent banana peel biomass with statin (Cln)

\begin{tabular}{|c|c|c|c|c|}
\hline \multirow{2}{*}{$\begin{array}{l}\text { Micro- } \\
\text { nutrient }\end{array}$} & \multicolumn{3}{|c|}{ Present study (mg/ $100 \mathrm{~g})$} & \multirow[t]{2}{*}{ Reference (mg/ $100 \mathrm{~g})$} \\
\hline & Fba & NInSc & Cln & \\
\hline \multirow[t]{2}{*}{$\mathrm{K}$} & 2795.5 & 2265.5 & 955.5 & 7810 ( Mohapatra et al., 2010) \\
\hline & & & & 220 (Ramirez-Orduna et al., 2005) \\
\hline \multirow[t]{2}{*}{$\mathrm{Ca}$} & 316.2 & 659.2 & 582.2 & 19 (Mohapatra et al., 2010) \\
\hline & & & & 260 (Ramirez-Orduna et al., 2005) \\
\hline \multirow[t]{2}{*}{$P$} & 71.0 & 141.7 & 125.6 & 283.1-432.1 (Khwas \& Deka, 2016) \\
\hline & & & & 270 (Ramirez-Orduna et al., 2005) \\
\hline \multirow[t]{3}{*}{$\mathrm{Mg}$} & 165.7 & 244.7 & 168.7 & 76.2 (Mohapatra et al., 2010) \\
\hline & & & & 138.1-214.0 (Khwas \& Deka, 2016) \\
\hline & & & & 170 (Ramirez-Orduna et al., 2005) \\
\hline B & 11.2 & 13.5 & 0.1 & - \\
\hline Al & 4.8 & 8.2 & 5.3 & - \\
\hline \multirow[t]{2}{*}{$\mathrm{Fe}$} & 1.5 & 12.5 & 7.7 & 1.8-3.0 (Khwas \& Deka, 2016) \\
\hline & & & & 35 (Ramirez-Orduna et al., 2005) \\
\hline \multirow[t]{2}{*}{$\mathrm{Mn}$} & 2.4 & 3.3 & 2.1 & 1.59 (Khwas \& Deka, 2016) \\
\hline & & & & 3 (Ramirez-Orduna et al., 2005) \\
\hline \multirow[t]{2}{*}{$\mathrm{Cu}$} & 0.4 & 1.4 & 0.2 & 0.11 (Khwas \&Deka, 2016) \\
\hline & & & & 0.9 (Ramirez-Orduna et al., 2005) \\
\hline
\end{tabular}

Table 1

b:RI-HPLC analysis of sugars $P$. cenararia PPT and aqueous waste

\begin{tabular}{|lll|}
\hline \multirow{2}{*}{ Sample } & $\%$ & \\
\cline { 2 - 3 } & Glucose & Sucrose \\
\hline PPT $2 \mathrm{mg} / \mathrm{mL}$ & - & 84.86 \\
\hline aqueous-extract $100 \mathrm{mg} / \mathrm{mL}$ & 1.22 & 2.36 \\
\hline
\end{tabular}


Table 1

c:HPLC-PDA and HRMS of compounds in the aqueous extract of $P$. cenararia

\begin{tabular}{|l|lllll|}
\hline RT & Compounds & $\%$ & HRMS (QTOF) & Formulae \\
\hline 2.74 & Epicatechin & $0.068 \pm 0.03$ & 306.06595 & $\mathrm{C}_{15} \mathrm{H}_{14} \mathrm{O}_{7}$ \\
\hline 2.77 & Gallic acid & $0.29 \pm 0.05$ & 170.01425 & $\mathrm{C}_{7} \mathrm{H}_{6} \mathrm{O}_{5}$ \\
\hline 2.96 & Quercetin & $0.34 \pm 0.06$ & $\mathrm{ND}$ & $\mathrm{C}_{15} \mathrm{H}_{10} \mathrm{O}_{7}$ \\
\hline 11.90 & Epigallocatechin & $0.091 \pm 0.03$ & 306.06595 & $\mathrm{C}_{15} \mathrm{H}_{14} \mathrm{O}_{7}$ \\
\hline 24.35 & Rutin & $0.141 \pm 0.01$ & 610.14581 & $\mathrm{C}_{27} \mathrm{H}_{30} \mathrm{O}_{16}$ \\
\hline 26.68 & Ellagic acid & $0.141 \pm 0.01$ & $\mathrm{ND}$ & $\mathrm{C}_{14} \mathrm{H}_{6} \mathrm{O}_{8}$ \\
\hline 3.2 Effect of natural inhibitor on yeast cell morphology
\end{tabular}

The SEM pictures of cells clearly signified the changes in cell membrane integrity. In the presence of inhibitor, cells shrank and distorted with wrinkled cell appearance. In the treatment of inhibitor, the cell size was diminished $(1.014 \mu \mathrm{m}$ breath and $1.825 \mu \mathrm{m}$ length of the cell) at $200 \mathrm{mM}$ rosuvastatin as compared to control ( $2.129 \mu \mathrm{m}$ breath and $2.807 \mu \mathrm{m}$ length) Addition of inducer has influenced the changes in cell structure (Fig. 1). Due to the presence of natural inhibitor, the structure of yeast cells was enlarged and normal in the shape; hence there was no shrinkage or crumbling of the cell surface as compared to the cells treated with the chemical inhibitor.

\subsection{Effect of inhibitor on yeast biomass and lipid yield}

The dry yeast biomass and lipid yield are measured after 3 days $(72 \mathrm{~h})$ of fermentation broth in the presence of chemical and natural inhibitors (Table 2a). Highest values in the biomass of $26.99 \mathrm{~g} \mathrm{~L}^{-1}$ were obtained using natural inhibitor followed by the chemical inhibitor $\left(24.04 \mathrm{~g} \mathrm{~L}^{-1}\right)$. Whereas, total lipid and extracellular lipid content were highest in chemical inhibitor $(30.9,22.5 \%)$ followed by natural inhibitor $(25.18,21.12 \%)$, respectively. Due to the present focus on natural inhibitor, the different solvents were tried for the economical way of extraction of lipid (Table $2 b$ ). The Soxhlet extraction using hexane was provided the total lipid $25.68 \%$ and extra-cellular lipid of $22.14 \%$. Therefore, this solvent was tried in cold percolation method, the yield of total lipid and extracellular lipid was 24.72 and $21.92 \%$, respectively. On the other hand, liquid $\mathrm{CO}_{2}$ was given a higher yield of total lipid (35.54\%) and extra-cellular lipid (30.17\%). In paired samples test using SPSS software, the paired difference between control and natural inhibitor with ethyl acetate extraction, natural inhibitor with hexane extraction, natural inhibitor with soxhlet extraction, and natural inhibitor with liquid $\mathrm{CO}_{2}$ extraction were greater than zero at $95 \%$ confidence level. Correlation analysis was also performed for fatty acid content, 0.05 level correlation 
between myristic and palmitic acid and 0.01 level of correlation was reported for myristic and behenic acid content (Table S1-S3).

Table 2

a: Effect of chemical and natural inhibitor onthe yeast biomass production $(\mathrm{g} / \mathrm{L})$, total lipid content (\%) and extra-cellular lipid (\%) using Soxhlet extraction

\begin{tabular}{|llll|}
\hline Sample & Control & Chemical Inhibitor & Natural Inhibitor \\
\hline Biomass g/L & $22.63 \pm 0.23$ & $23.04 \pm 0.42$ & $27.99 \pm 0.25$ \\
\hline T. lipid content (\%) & $22.36 \pm 0.16$ & $29.9 \pm 0.43$ & $25.68 \pm 0.83$ \\
\hline E. cellular lipid content (\%) & $19.09 \pm 0.01$ & $23.5 \pm 0.19$ & $22.64 \pm 0.02$ \\
\hline \% calculated from dry yeast biomass & & \\
\hline
\end{tabular}

Table 2

b: Effect of natural inhibitor on the production total lipid and extracellular lipid using different extraction processes

\begin{tabular}{|lll|}
\hline Sample & Total lipid (\%) & Extra-cellular lipid (\%) \\
\hline Soxhlet (ethylacetate) & $23.54 \pm 0.83$ & $21.12 \pm 0.02$ \\
\hline Soxhlet (hexane) & $25.68 \pm 0.77$ & $22.64 \pm 0.03$ \\
\hline Percolation (hexane) & $24.72 \pm 1.03$ & $21.92 \pm 0.03$ \\
\hline Liquid $\mathrm{CO}_{2}$ & $35.54 \pm 0.63$ & $30.17 \pm 0.73$ \\
\hline
\end{tabular}

\subsection{Fatty oil estimation}

In dried fresh-peel (F), spent-peel (P) (residue obtained after $P$. cineraria aqueous treatment) and spentpeel (S) (residue obtained after rosuvastatin treatment) are used for the recording of FT-IR spectra (Fig. 2). The intensity of $-\mathrm{OH}$ at $3434 \mathrm{~cm}^{-1}$ was more prominent in spent-peel (S). The stretching vibrations of -CH gave a sharp peak at $2923 \mathrm{~cm}^{-1}$. The diketones stretching vibrations of carbohydrate group and bending vibration of the absorbed water at $1626 \mathrm{~cm}^{-1}$ were recorded. Amine functional group was recorded only in the unspent dried banana peel biomass at $778.2 \mathrm{~cm}^{-1}$. Whereas, rosuvastatin treated biomass sample has an acid chloride group peak $(\mathrm{C}-\mathrm{Cl})$ at $625.8 \mathrm{~cm}^{-1}$. On the other hand, the stretching aromatic ring $(C=C)$ functional group was recorded at $1531.3 \mathrm{~cm}^{-1}$ in the $P$. cineraria treated sample. Another peak due to bending vibration of alkanes $\left(\mathrm{CH}_{2}, \mathrm{CH}_{3}\right)$ was seen in between 1383.8-1443.6 $\mathrm{cm}^{-1}$. The presence of polysaccharides (pyranose ring $\mathrm{C}-\mathrm{O}-\mathrm{C}$ stretching vibrations) has appeared in the range of 1033.4 to $1069.5 \mathrm{~cm}^{-1}$, which was due to the reducing sugars.

The saturated and unsaturated lipid composition is estimated using ${ }^{1} \mathrm{H}-\mathrm{NMR}$ (Figure S1). There were ten fatty acids identified in different extracts through GC-FID and GC/MS (Table 3). The saturated fatty acids (SFA: $57.31 \%$ ), monounsaturated fatty acids (MUFA: $18.92 \%$ ) and polyunsaturated fatty acids (PUFA: $16.75 \%$ ) were recorded in control sample. Similarly, the chemical inhibitor sample was contained SFA 
(63.44\%), MUFA (20.57\%), and PUFA (9.36\%), respectively. Besides, the natural inhibitor sample extracted in different solvents such as ethyl acetate, hexane and liquid $\mathrm{CO}_{2}$ were contained SFA $(55.07,50.63$, 45.81\%), MUFA (21.89, 22.61, 23.8\%) and PUFA (19.89, 19.86, 22.66\%), respectively (Fig. 3a). In TGA evaluation, the yeast oil is volatilized at low temperature and then followed by soybean oil (Fig. 3b).

Table 3

Fatty acid profile of chemical as well as natural inhibitor lipids extracted using different solvents

\begin{tabular}{|llllll|}
\hline Fatty acids & Control & Cln & NInEa & NInHx & NInSc \\
\hline Myristic (14:0) & 6.43 & 3.85 & 6.45 & 6.84 & 7.29 \\
\hline Palmitic (16:0) & $\mathbf{2 2 . 3}$ & $\mathbf{2 8 . 3 9}$ & $\mathbf{2 5 . 2 5}$ & $\mathbf{2 5 . 0 6}$ & $\mathbf{2 5 . 8 6}$ \\
\hline Stearic (18:0) & 8.12 & 9.54 & 4.95 & 5.27 & 5.68 \\
\hline Oleic (18:1) & $\mathbf{1 7 . 8 2}$ & $\mathbf{1 8 . 7 4}$ & $\mathbf{1 8 . 6 9}$ & $\mathbf{1 8 . 9 4}$ & $\mathbf{1 9 . 8 8}$ \\
\hline Linolic (18:2) & $\mathbf{1 6 . 7 5}$ & $\mathbf{9 . 3 6}$ & $\mathbf{1 6 . 0 4}$ & $\mathbf{1 5 . 6 1}$ & $\mathbf{1 7 . 6 1}$ \\
\hline Linolenic (18:3) & - & - & 3.85 & 4.25 & 5.35 \\
\hline Arachidonic (20:0) & 13.5 & 10.27 & 5.2 & 4.15 & 3.25 \\
\hline Ecosenoic (20:1) & 1.1 & 1.83 & 3.2 & 3.67 & 4.12 \\
\hline Behanic (22:0) & 3.26 & 4.72 & 6.24 & 4.22 & 1.56 \\
\hline Lignoceric (24:0) & 3.70 & 6.67 & 6.98 & 5.09 & 1.77 \\
\hline Total & $\mathbf{9 2 . 9 8}$ & $\mathbf{9 3 . 3 7}$ & 96.85 & 93.1 & 92.27 \\
\hline SFA & 57.31 & 63.44 & 55.07 & 50.63 & 45.21 \\
\hline MUFA & 18.92 & 20.57 & 21.89 & 22.61 & 24.0 \\
\hline PUFA & 16.75 & 9.36 & 19.89 & 19.86 & 22.96 \\
\hline Cln: Chemical inhibitor extracted using hexane; NlnEa: Natural inhibitor extracted using ethyl acetate; & \\
\hline NInHx: Natural inhibitor extracted using hexane; NlnSc: Natural inhibitor extracted using liquid CO 2 \\
\hline
\end{tabular}

\subsection{Quantitative analysis of polyphenols-flavonoids and sugars in $P$. cineraria pod extract}

The results of the RI-PDA-HPLC analysis of the aqueous extract of $P$. cineraria pod, sucrose $(2.3 \%)$ and glucose $(1.2 \%)$ were the primary components in the extract, and fewer polyphenols such as gallic acid $(0.29 \%)$, quercetin $(0.34 \%)$, rutin $(0.14 \%)$, and ellagic acid $(0.14 \%)$ were also present in the aqueous extract (Table $1 \mathrm{~b}$ and $1 \mathrm{C}$ ).

\subsection{Isolation of reducing sugars from $P$. cineraria}


The precipitate was contained sucrose (84.86\%). Further, the glucose and sucrose were isolated and spectroscopically characterized. The glucose and sucrose in the aqueous extract were quantified through HPLC (Figure S2). The devolatilization behavior of isolated glucose and sucrose are fully matched with the pure standards as depicted through TGA and DTG (Figure S3). The discoloration of initial media after treatment with $P$. cineraria aqueous water is presented in Fig. 4.

\section{Discussion}

\subsection{Importance of substrate and inhibitor}

The banana peel was contained a high amount of organic matter $(91.5 \%)$ and minerals. It contained $30 \%$ of starch and $4.41 \%$ of protein. It is a good source of many essential nutrients as presented in Table $1 \mathrm{~b}$. Banana peel has appropriate amounts of nutrients for the regular growth of oleaginous yeast. Thus, it is used throughout the experiment as a carbon source in the production media. The single cell oil (SCO) produced from cell factories of yeast is followed lipid production pathway, and an alternative competing mevalonate pathway produces ergosterol pigment formation. To inhibit the pathway for ergosterol formation, the activity ofa key enzyme HMG CoA reductase needs manipulation. Similarly, the mevalonate pathway is inside human and animals are responsible for cholesterol formation. So, to increase the flux towards fatty acid production, the competing mevalonate pathway inhibition through HMG CoA reductase(inhibitor) should be done. For this chemical inhibitor rosuvastatin has been used in humans [13], and animals for a long, but its side effects were also being reported.In our previous work on oleaginous yeast, the chemical inhibitor rosuvastatin has also been used to increase lipid production [4].

Due to the side effect of rosuvastatin and for the safe production of lipid, the plant origin P. cinararia aqueous waste extract as a natural inhibitor has been tried in the present work. P. cinararia pod contains $5.44 \%$ of protein, carbohydrate, phenyl propenoids and other bioactive compounds. Due to the nutraceutical value of the pod and its aqueous washing part is discarded in food preparation. It is assumed that by inhibiting the enzyme HMG CoA reductase, the aqueous extract of $P$. cineraria may be effective to enhance the lipid accumulation in the yeast. The addition of the $P$. cineraria aqueous extract in 10, 50, 30, 40 and $50 \mathrm{~mL}$ (Fig. 4b), and it was observed to inhibit the competitive pathway in $100 \mathrm{~mL}$ media. The optimum result was noticed in $30 \mathrm{~mL}$, and it was used throughout the experiment. As reported, inside human and animal hypercholesteremic alignments are being treated through $P$. cineraria $[14,15]$. Due to hypercholesteremic activity of $P$. cineraria aqueous extract, our group explores this as a natural inhibitor for enhancing biomass production with a higher accumulation of lipid. This attempt of using a natural inhibitor for HMG CoA reductase enzyme inhibition in oleaginous yeast is studied first time to the best of our knowledge. The total dis-colouration is seen by using this waste $P$. cineraria pod aqueous extract (Fig. 4a). In the present analysis, it found that the aqueous extract was contained glucose $(1.22 \%)$, sucrose $(2.36 \%)$, protein $(3.77 \%)$ along with epicatechin $(0.068 \%)$, gallic acid $(0.29 \%)$, quercetin $(0.34 \%)$, epigallocatechin $(0.091 \%)$, rutin $(0.141 \%)$, and ellagic acid $(0.141 \%)$ might be facilitated for enhancing higher lipid accumulation by the yeast cell (Fig. 4b). The natural inhibitor was produced higher biomass (27.99\%) as compared to the chemical inhibitor (24.04\%) (Table 2a). But the 
chemical inhibitor was produced an enhanced percentage of total lipid and extra-cellular lipid (30.9, $23.5 \%)$ as compared to the natural inhibitor $(25.68,22.64 \%)$, respectively. As interpreted, the rosuvastatin is given more stress to the $R$. mucilaginosa, so the overall biomass production is not improved and only accumulated higher fatty acid to overcome the stress as observed in SEM pictures. On the other hand, the natural inhibitor was provided a better environment for a significant increase of biomass as well as lipid. Hence, the overall enhancement of the total lipid is $21.3 \%$ in natural inhibitors, whereas total lipid is $18.2 \%$ in the chemical inhibitor sample (Table $2 b$ ).

\subsection{Importance of green extraction methods}

The extraction of lipid from oleaginous yeast is a difficult task due to its lipid being trapped inside the cell, which is bound by the hard cell wall. This lipid is tried to extract using different organic solvents such as $\mathrm{CH}_{3} \mathrm{Cl}, \mathrm{CH}_{2} \mathrm{Cl}_{2}$, ethyl acetate, and hexane. It was found that the ethyl acetate and hexane gave significant yield. Due to the prohibited nature of $\mathrm{CHCl}_{3}$ and $\mathrm{CH}_{2} \mathrm{Cl}_{2}$ in industrial application, these solvents were not considered for optimization study. Ethyl acetate and hexane gave comparable amounts of lipids (Table 2b). Lipids are generally non-polar in nature; hence hexane gave a slightly higher yield as compared to the semi-polar ethyl acetate through the percolation method. For complete isolation of lipids, the soxhlet extraction in hexane has been tried and gave maximum yield in $8 \mathrm{~h}$, and then after there was no significant increase of lipid yield. Thus, the percolation as well as soxhlet extraction was not suitable for the complete isolation of lipids due to difficulty in penetration of solvent inside the hard cell wall. The liquid $\mathrm{CO}_{2}$ extraction has completely isolated the lipids (35.54\%) due to their superior solvation properties. Liquid $\mathrm{CO}_{2}$ has gas-like properties such as high diffusion, low surface tension with medium density and non-polar nature makes it an excellent solvent for dissolving the lipids inside the cell, hence facilitating complete extraction of lipids. These properties are helped to enhance the yield of lipids by about $30 \%$, and having greener along with GRAS properties encourages use in food products. These findings were also been supported by our previous work that, there is no need of removal of extracting solvents, improving the yield and most suitable to extract the thermo-sensitive compounds, higher selectivity, shorter extraction time and no need to involve toxic organic solvents, low cost, non-flammable, non-toxic $[12,16]$. By the liquid- $\mathrm{CO}_{2}$ extraction, the smaller chain fatty acids were easily been extracted through this method as a comparison with solvent extraction. Lack of longer chain fatty acid like behenic and lignoceric fatty acids in the procured oil makes the overall lipid suitable more for the food grade quality.

\subsection{Quality of fatty acids for nutrition}

The fatty oil quality is determined by GC-FID and GC/MS analysis as presented in Table 3. The results of ${ }^{1} \mathrm{H}-\mathrm{NMR}$ are in agreement with the GC-FID and GC/MS. Since, ${ }^{1} \mathrm{H}-\mathrm{NMR}$ based process analyses the neat microbial oil so no need to convert the fatty acids into their methyl ester form [17]. The higher percentages of unsaturated fatty acids (MUFA and PUFA) were considered as a preferable combination [16]. This higher UFA not only enhances the glucose metabolism and equilibrium of insulin but also lessens cardiac issues [18]. Liquid- $\mathrm{CO}_{2}$ extraction was giving an enhanced yield of lipids (35.54\%) in $4 \mathrm{~h}$ due to superior salvation properties. The novelty for using mevalonate pathway rate limiting enzyme 
HMG CoA reductase inhibition with the use of natural inhibitor $P$. cineraria by showing it for completed is coloration of the production media (Fig. 4a). The similar discoloration was observed when rosuvastatin a chemical inhibitor was used for inhibition of HMG CoA reductase enzyme in previous work [5]. It observed that the biomass (banana peel) was better utilized in the chemical inhibited process as compared to the chemical inhibitor. The chloride was detected in chemical inhibited residue along with rosuvastatin residues, which impact higher stress on yeast cell-wall (Fig. 2). Thus, the cell-wall is rigid with a higher accumulation of SFA, this combination might be provided better protection to yeast. On the other hand, the natural inhibited residue contained more unsaturated groups, higher yeast biomass yield and higher accumulation of UFA. The lipid is also profitably isolated from the yeast biomass (Table 2a). The acid value $\left(1.2 \mathrm{mg} \mathrm{g}^{-1} \mathrm{KOH}\right)$, saponification value $\left(172 \mathrm{mg} \mathrm{g}^{-1} \mathrm{KOH}\right)$, and iodine value $(82 \mathrm{~g} / 100 \mathrm{~g})$ were fallen in the range of the vegetable oil.

This solvent helped to screen out the high molecular SFA like behenic acid (1.56\%) and lignoceric acid $(1.77 \%)$, these fatty acids at higher percentage are not recommended for food applications due to their adverse impact in cardiac related issues. In our previous work, it was reported the chemical inhibitor like $\mathrm{NaCl}$ and ionic liquid in isolation or combination were shifted the flux towards the accumulation of a higher percentage of SFA in a yeast cell. This SFA may be provided better protection from cell membrane osmosis [5]. In reverse, the natural inhibitor encouraged yeast for the production of UFA, which may be influenced by the phytomolecules of $P$. cineraria aqueous extract.

The liquid- $\mathrm{CO}_{2}$ extracted oil was contained an improved percentage of low molecular fatty acids such as myristic $(7.29 \%)$ and palmitic $(25.86 \%)$ along with MUFA (24.0\%) and PUFA (22.96\%), so it volatilized at $375^{\circ} \mathrm{C}$. On the other hand, soybean oil was devolatilized at $425^{\circ} \mathrm{C}$. Overall, the liquid- $\mathrm{CO}_{2}$ extracted yeast oil is suitable for edible purposes. This is a novel finding to manipulate the production of UFA through $\mathrm{SCO}$ and liquid- $\mathrm{CO}_{2}$ extraction made the process interesting.

\subsection{Mechanism of the mode of action}

Novelty for using mevalonate pathway is the rate limiting enzyme HMG CoA reductase inhibition with the use of natural inhibitor $P$. cineraria by showing the complete discolouration in production medium through waste management approach (Fig. 4). The similar discolouration was observed when rosuvastatin was used for inhibition of HMG CoA reductase enzyme. The phytocompounds epicatechin, gallic acid, quercetin, epigallocatechin, rutin, ellagic acid, glucose and sucrose in the aqueous $P$. cineraria extract as detected through NMR, FTIR, and HPLC techniques were responsible for HMG CoA reductase inhibition as well as sugars helped in the initial nourishment of the yeast. The flavonoids are identified in the aqueous extract of $P$. cineraria pods (Table 1c), could be responsible for the pathway inhibition.

Generally, overnight soaked pods of $P$. cineraria aqueous extract are usually discarded as waste and the same as in the case with banana peel waste but it can be utilized not only to enhance the lipid production in oleaginous yeast but also for the benefit of human health suffering from hypercholesteremic diseases. In other words, 'best out of waste' can be made is appropriate for this approach along with a greener approach for the environmental benefit. 


\section{Conclusion}

The yeast SCO was produced using banana peel and further enhanced the yield through natural inhibitor $P$. cineraria waste aqueous extract. The glucose, sucrose and mineral nutrients in both the wastes are responsible for the easy growing of oleaginous yeast. The phyto-molecules such as might be responsible for enhancing growth as well as accumulation of higher fatty oil. The significant growth of yeast was not observed when applying a chemical inhibitor. Hence, a higher lipid yield (21\%) was given by the natural inhibitor sample. This observation was noticed in the SEM pictures that the chemical inhibitor was influenced to shrink the yeast cell. Unlike chemical inhibitors (rosuvastatin), the natural inhibitor has shifted the flux to accumulate the w-3-fatty acid (linolenic acid), which is a precursor for the synthesis of vitamin-E. Different conventional organic solvents have been tried for the extraction of fatty oil, but hexane was found to be most suitable and already practiced for the isolation of fatty oil from oilseeds on an industrial scale. The isolation of fatty oil from chemical inhibitor cells was difficult as compared to natural inhibitor one. The percolation method is energy-efficient as compared to the soxhlet method, and the former can be used in the scale-up process. In addition, liquid $\mathrm{CO}_{2}$ has been given the highest yield

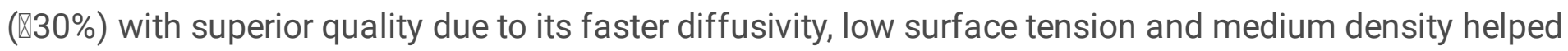
for leaching out lipid from hard cell-wall yeast glands. Thus, liquid- $\mathrm{CO}_{2}$ was helped for selective isolation of improved percentage of MUFA (24.0\%), and PUFA (22.96\%) with fewer percentages of high SFA (45.21\%) like behenic acid (1.22\%) and lignoceric acid (1.77\%). Liquid- $\mathrm{CO}_{2}$ extract was enriched with low molecular fatty acids and UFA (46.96\%), hence is an ideal composition for the nutritional purpose.

\section{Declarations}

\section{Funding}

The first author (Shivani Chaturvedi) is grateful for the financial support from the University grant commission Post-doctoral fellowship program, UGC award letter-number F.15-1/2017/PDFWM-2017-18DEL-3915 (SA-II) from UGC, India.

\section{Authors' contributions}

Shivani Chaturvedi, along with Prashant Kumar, Deepak Kumar, Madhuri Gupta, and Nazia Sayed have done experimentation, prepare the original draft. Prasant Kumar Rout, Sunil K. Khare contributed in editing and supervision of the work.

\section{Acknowledgments}

The authors are thankful to Director, CSIR-CIMAP, Lucknow for phytochemical as well as lipids profiling, and grateful to Dr Lata Nain of IARI PUSA, New Delhi for providing constant guidance.

\section{Consent for publication}


The authors declare that the research work was conducted, without any commercial or financial relationships, which may be construed as potential conflicts of interest. We confirm that no part of this work has been submitted in any other journal and the authors have no conflict of interest. All the authors have consented to the submission of this manuscript. All data generated are analyzed during this study are included in this published article (and its supplementary information files).

\section{Availability of data and materials}

The datasets supporting the conclusions of this article are included in the main manuscript. The authors promise to provide any missing data on request.

\section{Conflicts of interests}

All authors declare that they have no conflicts of interest.

\section{References}

1. Mohanty, C.S., Syed, N., Kumar, D., Khare, S., Nayak, S.P., Sarvendra, K., Pattanayak, R., Pal, A., Chanotiya, C.S., Rout, P.K.: Chemical characterization of winged bean (Psophocarpus tetragonolobus (L.) DC. seeds and safety evaluation of its fatty oil. J Food Meas. Charact. 15, 807-816 (2021)

2. Chaturvedi, S., Bhattacharya, A., Nain, L., Prasanna, R., Khare, S.K.: Valorization of agro-starchy wastes as substrates for oleaginous microbes. Biomass Bioenerg 127, 105294 (2019)

3. Statista, 2021. Production volume of banana in India FY 2015-2020; https://www.statista.com/statistics/1038905/india-production-of-banana/

4. Chaturvedi, S., Sadaf, A., Bhattacharya, A., Rout, P.K., Nain, L., Khare, S.K.: Environment-friendly synergistic abiotic stress for enhancing the yield of lipids from oleaginous yeasts, Eur. J. Lipid Sci. Technol. doi:10.1002/ejlt.202000376 (2021)

5. Shivani Chaturvedi, A.K., Gupta, A., Bhattacharya, T., Dutta, L., Nain, S.K.. Khare.: Overexpression and repression of key rate limiting enzymes (Acetyl CoA carboxylase and HMG reductase) to enhance Fatty acid production from Rhodotorula mucilaginosa. J. basic microbiol. 1-11: (2020)

6. Ramkumar, S., Raghunath, A., Raghunath, S.: Statin therapy: review of safety and potential side effects. Acta Cardiol. Sin. 32, 631-639 (2016)

7. Kumar, L., Prasad, M., Arya, D., Bhagour, K.: In vitro and in vivo antidiabetic activity of isolated fraction of Prosopis cineraria against streptozotocininduced experimental diabetes: a mechanistic study. Biomed. Pharmacother. 108, 1015-1021 (2018) 9

8. Janbaz, K.H., Haider, S., Imran, I., Zia-Ul-Haq, M., De Martino, L., De Feo, V.: Pharmacological evaluation of Prosopis cineraria (L.) Druce in gastrointestinal, respiratory, and vascular disorders. Evid. Based Complement Alternat. Med. 10, 1-7 (2012)

9. Liu, Y., Singh, D., Nair, M.G.: Pods of Khejri (Prosopis cineraria) consumed as a vegetable how ed functional food properties. J. Functional Foods. 4, 116-121 (2012) 
10. Prakash, O., Naik, M., Katiyar, R., Naik, S.N., Kumar, D., Maji, D., Shukla, A., Nannaware, A.D., Kalra, A., Rout, P.K.: Novel process for isolation of major bio-polymers from Mentha arvensis distilled biomass and saccharification of the isolated cellulose to glucose. Ind. Crops Prod. 119, 1-8 (2018)

11. Gupta, V.K., Tuohy, M.G., Ayyachamy, M., Turner, K.M., O’Donovan, A.: Laboratory protocol in fungal biology. Springer science and business media (2012)

12. Rout, P.K., Naik, S.N., Rao, Y.R.: Liquid $\mathrm{CO}_{2}$ extraction of flowers of Pandanus fascicularis Lam and fractionation of floral concrete and comparative composition of the extracts. J. Food Biochem. 35, 500-512 (2011)

13. Jain, P.G., Patil, S.D., Haswani, N.G., Girase, M.V., Surana, S.J.: Hypolipidemic activity of Moringa oleifera Lam., Moringaceae, on high fat diet induced hyperlipidemia in albino rats. Rev. Bras. Farmacogn. 20(6), 969-973 (2010)

14. Elshazly, M.B., Stegman, B., Puri, R.: Regression of coronary atheroma with statin therapy. Curr. Opin. Endocrinol. Diabetes Obes. 23, 131-137 (2016)

15. Pareek, A.K., Garg, S., Kuma, M.: Prosopis cineraria: A gift of nature for pharmacy. Int. J. Pharm. Sci. 6, 958-964 (2015)

16. Pradhan, R.C., Naik, S.N., Rout, P.K., Dalai, A.K., Meda, V.: Supercritical carbon dioxide extraction of wheat distiller's dried grain with solubles. Int. J. Food Sci. Nutr. 61, 829-836 (2010)

17. Knothe, G., Kenar, J.A.: Determination of the fatty acid profile by $1 \mathrm{H}-\mathrm{NMR}$ spectroscopy. Eur. J. Lipid Sci. Technol. 106, 88-96 (2004)

18. Budai, Z., Balogh, L.: Short-term fat meal intake alters the expression of circadian clock, inflammation, and oxidative stress-related genes in human skeletal muscle. Int. J. Food Sci. Nutr. 70, 749-758 (2019)

19. Mohapatra, D., Mishra, S., Sutar, N.: Banana and its by-product utilization: an overview. J. Sci. Ind. Res. 69, 323-329 (2010)

20. Ramírez-Orduña, R., Ramírez, R.G., González-Rodríguez, H., Haenlein, G.F.W.: Mineral content of browse species from Baja California Sur, Mexico. Small Ruminant Research. 57(1), 1-10 (2005)

21. Khawas, P., Deka, S.C.: Isolation and characterization of cellulose nanofibers from culinary banana peel using high-intensity ultrasonication combined with chemical treatment. Carbohydrate Polymers. 137, 608-616 (2016)

\section{Figures}



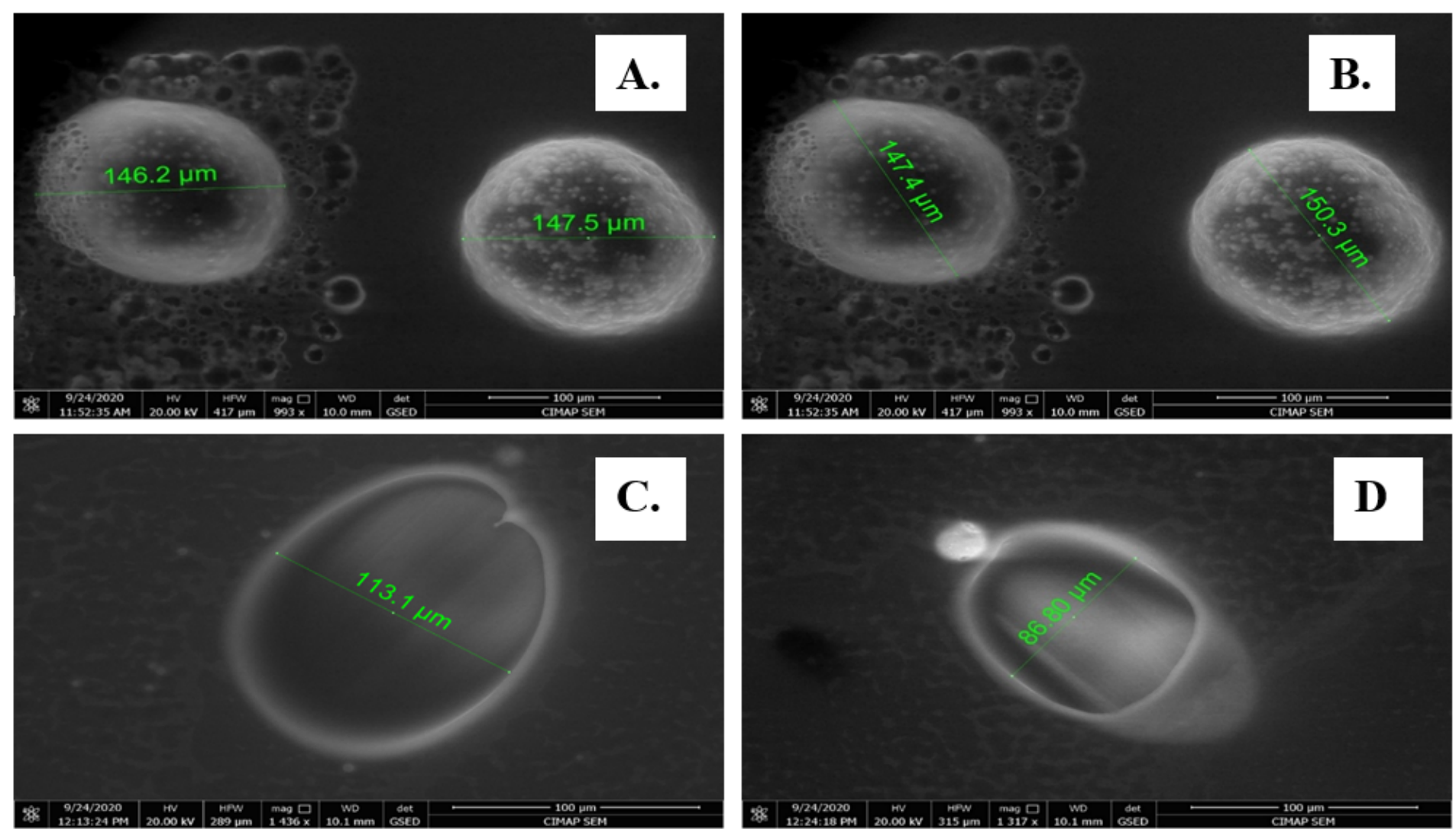

\section{Figure 1}

Comparative SEM images (A) Lipid filled R. mucilaginosa cells as control lengthwise size (B) Lipid filled R. mucilaginosa cells as control diagonal size; (C) Lipid filled R. mucilaginosa cells under natural inhibitor (P. cineraria) influence; (D) Yeast cell after rupturing due to overload of lipids after treating with natural inhibitor. 


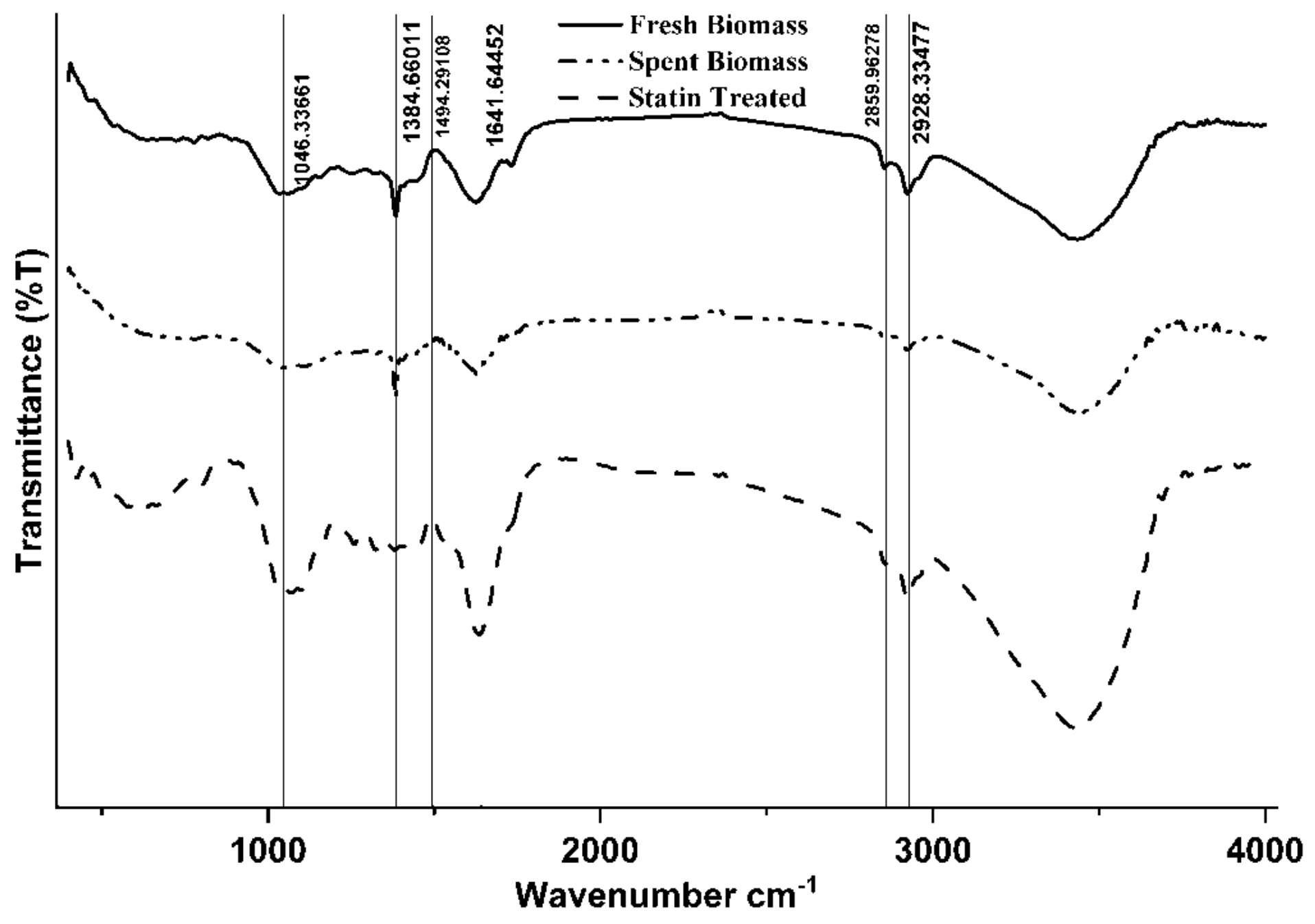

Figure 2

Comparative FTIR spectra (a) Fresh dried banana peel biomass; (b) Spent banana peel biomass along with Prosopis cineraria waste water; (c) Spent banana peel biomass with statin 

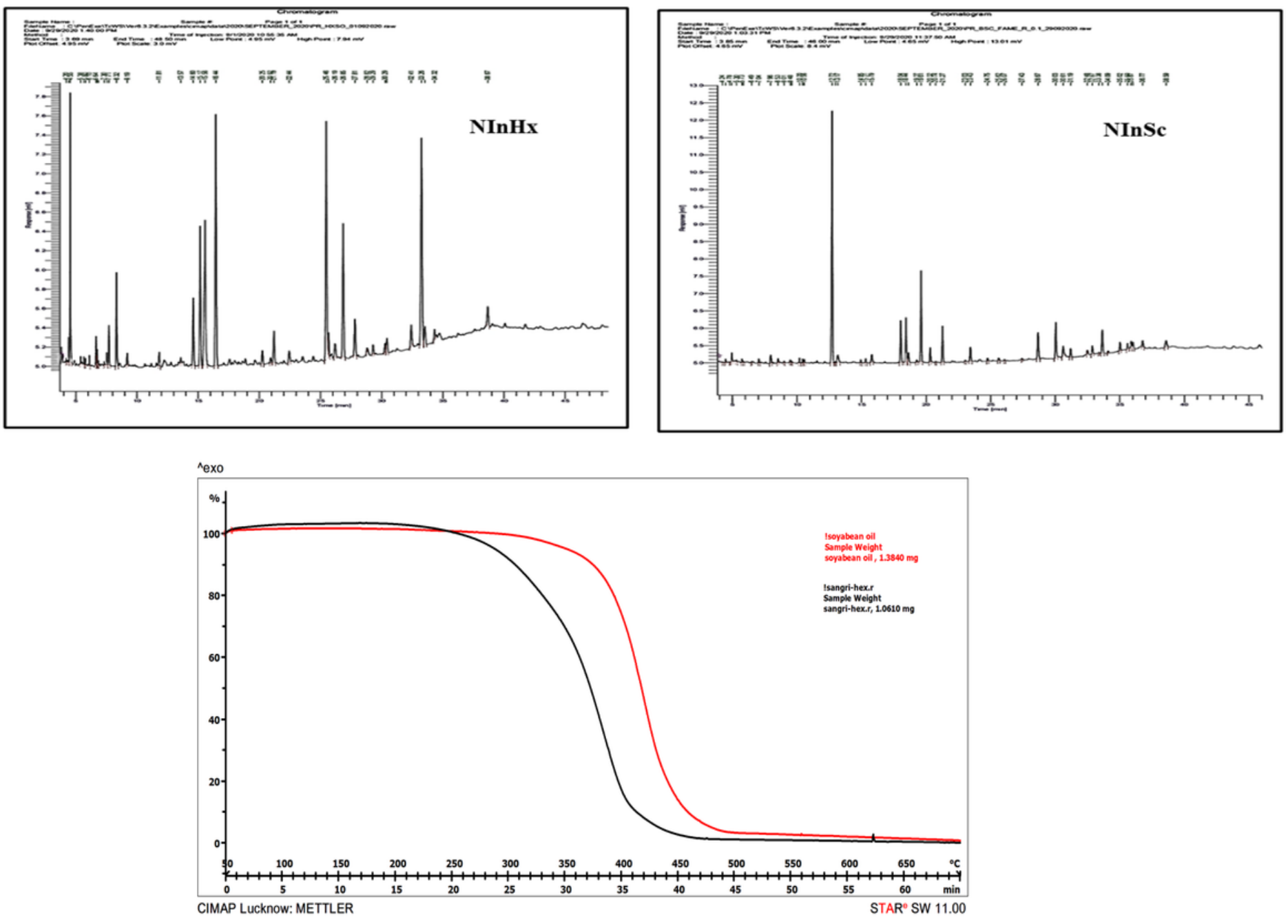

Figure 3

GC spectra of FAME (A) Natural inhibitor hexane extraction (NInHx); (B) Natural inhibitor CO2extraction (NInSc); (C) TGA of lipid Natural inhibitor $\mathrm{CO} 2$ extracted in comparison with soybean oil 


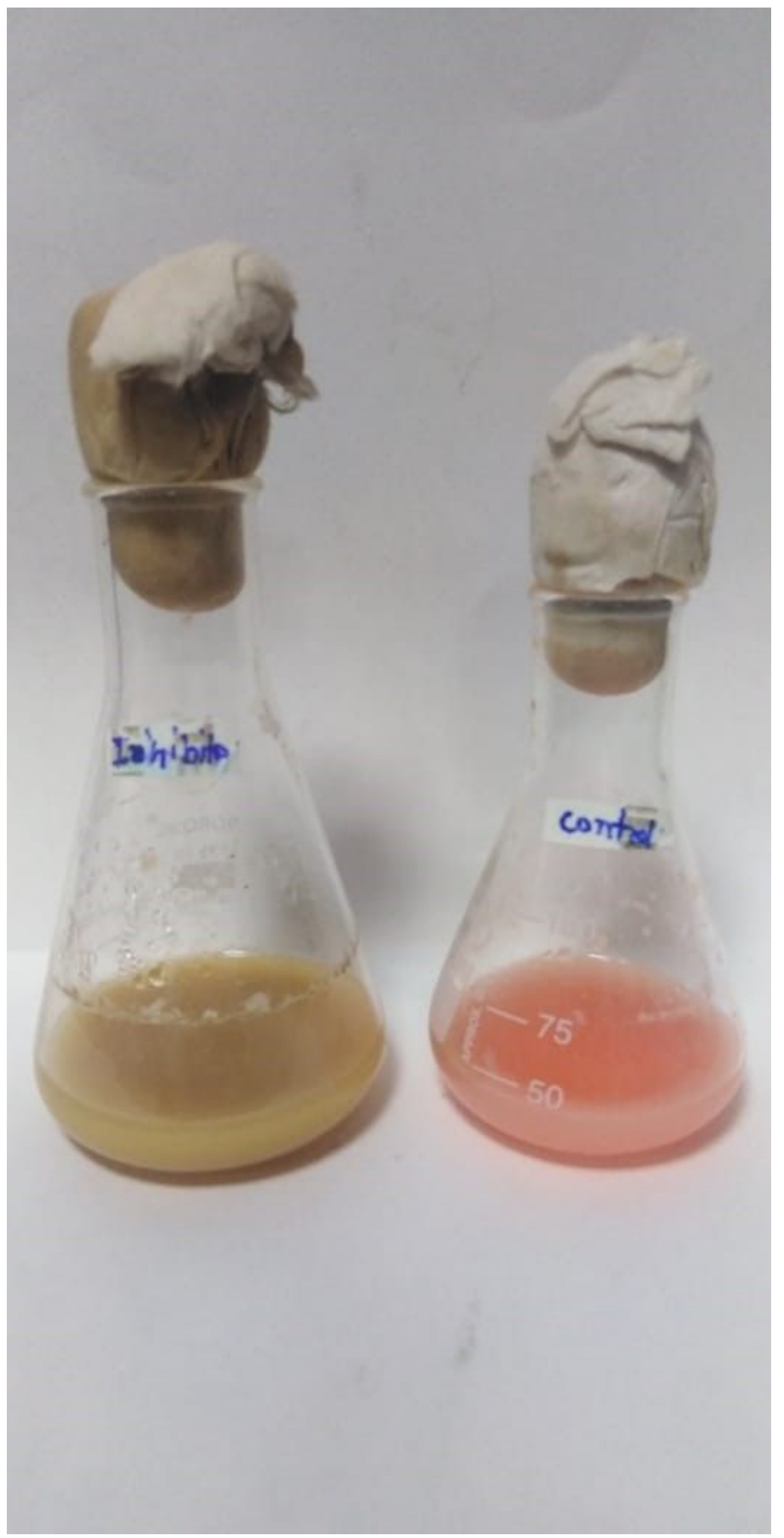

Figure 4

Effect of aqueous P. cineraria pod waste in production media influence discolouration 


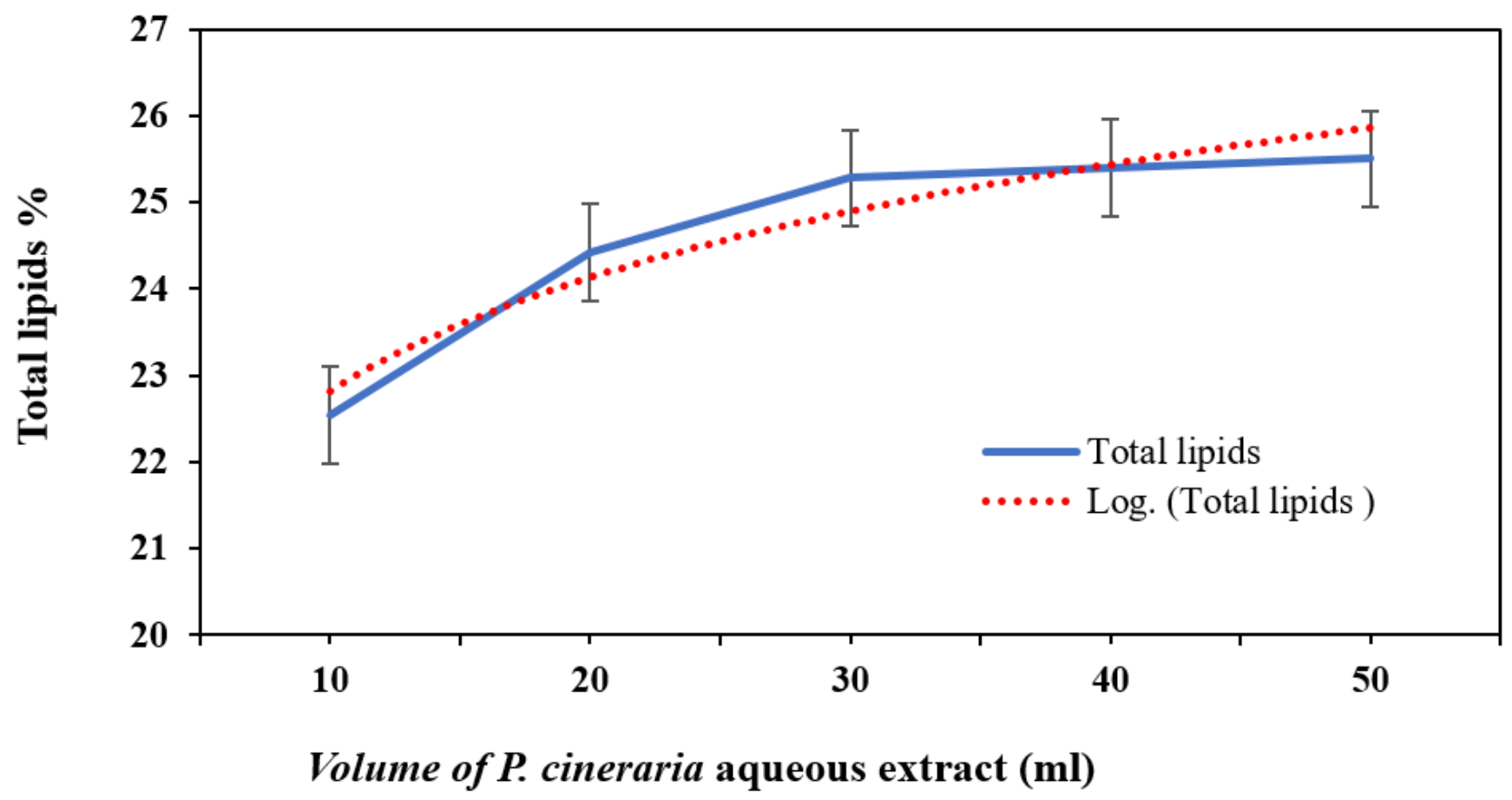

Figure 5

Effect of volume of P.cineraria aqueous extract on total lipids production.

\section{Supplementary Files}

This is a list of supplementary files associated with this preprint. Click to download.

- Scheme1.png

- Supplementaryfigures2.8..21.docx

- GAofSCpaper.pptx 